\title{
DIFFERENTIATION OF SOCIO-ECONOMICAL ENVIRONMENT AS FACTORS OF REGIONAL DEVELOPMENT (THE CASE STUDY OF MURMANSK REGION, RUSSIA)
}

\author{
Vera P. Samarina \\ Starły Oskol Technological Institute, Starły Oskol, Russia \\ Tatiana P. Skufina \\ Institute of Economic Problems of the Kola Science Centre of the Russian Academy of Sciences, \\ Apatity, Russia. \\ Aleksandr V. Samarin \\ Belgorod State National Research University, Belgorod, Russia \\ The inequality of the socio-economic space of the regions is a significant problem for the \\ management of the regional development of any country. The objective nature of the issue of \\ unequal socio-economic development, the lack of unified regulation approaches and methods \\ determine not only the practical meaning but also the scientific interest in considering the \\ specific manifestation of this problem on particular objects. The paper illustrates the \\ problem of differentiation in the socio-economic space of one Russian region by the data on \\ the Murmansk region, the subject of the Russian Arctic zone. To analyze the situation the
}

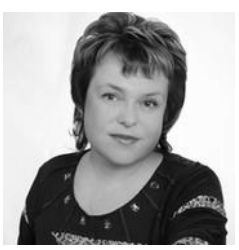

Samarina Vera

is a doctor of economical sciences (since 2010), professor of economy and management chair of Staryy Oskol technological institute research technical university «MISIS» The developer of a considerable quantity of branches of learning for universities, the author of 7 textbooks and manuals for universities with UMO classification. The founder and head of business school, based on Staryy Oskol technological institute research technical university «MISIS». The winner of the best scientific book competitions, organized by the fund of domestic education development in 2007, 2008, 2010, 2011; the expert of institute of a sustainable development of the Russian Federation public chamber. The member of editorial boards of three federal journals in Russia and Thailand. Her scientific interests are: planning and forecasting, social and economic development, nature management economy, regional economy, national economy branch, entrepreneurship, business processes. Since 2000 she has published more than 200 articles in Russian federal and international journals including 11 Scopus and web of science articles.

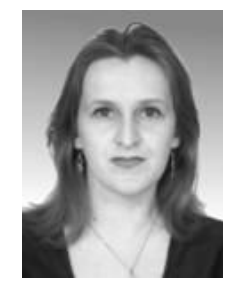

Skufina Tatiana

is a doctor of economical sciences (since 2007), professor (since 2013), director of the Luzin institute of economic studies of the Kola science centre, Russian academy of sciences. Her scientific interests are: public administration, regional economy, economic and mathematical modeling. The author of more than 250 articles in Russian federal and international journals, 25 monographs, 3 textbooks for universities. Expert of the Russian academy of sciences, member of the expert council on regional competitions of Russian foundation for basic research department of humanities and social sciences (economics section), expert of the Russian science foundation, member of the economic council under the governor of the Murmansk region, member of the public council under the ministry of economic development of the Murmansk region.

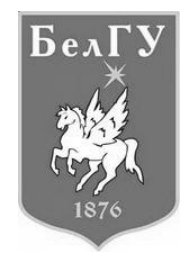

Samarin Alexander

is a candidate of philological sciences (since 2007), associate professor of philology department in Belgorod state research university (Staryy Oskol branch); the developer of a considerable quantity of branches of learning for universities; the author of 11 tutorials. His scientific interests are sociolinguistics, ethnolinguistics and cognitive linguistics. Since 2002 he has published more than 50 articles in Russian federal and international journals including 2 Scopus articles; participated in 45 international scientific-practical conferences. 
authors used integrated assessments, the relative strength index for each of the assessment indicators, and the Gini index. The authors have revealed the specifics in unequal socioeconomic development of the Murmansk region and the stable trends on the basis of which have developed recommendations for managing the regional social and economic development.

Keywords: differentiation, socio-economic development, trends, region of the Russian Federation, Murmansk region.

\section{Introduction}

The fundamental nature of the problem of unequal socio-economic development is determined by the constant contradiction between the management efforts of any country, region or municipality aimed at reducing the socio-economic imbalances of the entrusted territory and objective economy laws that reproduce and deepen the socio-economic space differentiation of any territorial object. However, the danger of growing differentiation, especially by social characteristics, can become a source of significant social problems and destabilize the socio-economic situation.

Therefore, the most important task is to conduct independent scientific investigations aimed at a detailed analysis of the real development of differentiation and the reveal of threats caused by the unequal socio-economic development of certain territorial entities.

The aim of the study given is to identify the specifics of the differentiation trends in the socio-economic space of the Russian Federation region through the case study of the Murmansk region and on this base to develop recommendations for the regional management.

Objectives: 1) to determine the approach and methods of studying the differentiation in the socio-economic space of the Murmansk region; 2) to reveal the specific development of the differentiation phenomenon in towns and districts of the Murmansk region; 3) to develop management recommendations for the development of the Murmansk region.

Research hypotheses: 1) system representation of a problem of inter-regional differentiation in the regional socio-economic space demands application of complex methodical assessment tools; 2) crisis processes determine the displacements in the ratio of the parameters of socio-economic development in towns and districts in the Murmansk region and lead to an increase of the differences in the economy and social sphere of this region; 3) the growth of differentiation in the socio-economic development of the Murmansk region determines the need for adjusting the policies and practices of managing the regional socio-economic development.

\section{Literature review}

The objective nature of the contradiction between the inevitable differences in the levels of socio-economic development of territorial subjects and management tasks requiring the leveling of these differences determines the contradiction of an economic theory. On the one hand, there is a huge number of works devoted to the problem of the unequal development of objects with different territorial level (large world regions, countries, regions of the country, cities). On the other hand, there are limited theories concerning development 


\section{DIFFERENTIATION OF SOCIO-ECONOMICAL}

and regulation of the phenomenon of unequal socio-economic territorial development and this is noted by a number of researchers (Kranich, 2015; Leonardi, 2005; Skufina, 2013) as well as their apparent insufficiency regarding the management practice needs (Coulibaly, 2007; Skufina, Baranov \& Samarina, 2016; Ushakov, 2016). It is for this reason that the current aimed at the formation of purely theoretical models oriented on solving the problem of differentiation of socio-economic space gradually lost its force (Corliss \&Lewis, 2014; Marsh, 2014). At the same time, the current is gaining momentum aimed at a detailed analysis of the real development of differentiation and identification of threats caused by the unequal socio-economic development of certain territorial subjects (Kranich, 2015; Skufina, 2013; Ushakov, 2016). The authors attribute this to the fact that, concurrently with the lack of the theory, a well-founded criticism of the current world order deepening the gap in the development of territories is formed within its framework, which establishes the danger of differentiation of the socio-economic space (Kranich, 2015; Skufina, 2013, Corliss \& Lewis, 2014). This criticism and the real demands of the practice in territorial development management remind of the old morality: "To defeat the old theory, it is not enough to subject its prerequisites to destructive criticism ... we must offer a new theory" (Blaug, 1997, p. 659). The operant motive from this morality is the accumulation and generalization of facts.

This determines the priority of the approach to the study of the inequality phenomenon based on successive movement: from a quantitative assessment of the space inequality phenomenon, through the identification of specific features, perhaps regularities, and to practical recommendations for management. It is within the framework of this approach that the authors propose their research.

\section{Research methodology}

The authors propose to use three methodologies based on three basic methods of investigating socio-economic inequality.

The first method is based on the method of ranking objects with the aim of constructing a comprehensive assessment. Within this method the authors propose to apply a technique called "average places" often used not only for research purposes but also for practical purposes of state regulation of territorial development. The sequence of iterations: 1) for each assessment indicator the rank of each object is determined - the best value (the first place), the worst value (the last place); 2) for each indicator of each object, a score is calculated (average value is zero) as the difference between the average value-rank and the rank of an object in the general ranking series; 3) for each object the scores are summarized by indicators with the subsequent division by the number of indicators.

It is generally accepted that the sought assessment objectively characterizes the state of each regional object in comparison with other objects. At the same time, it has an inherent drawback - it does not allow quantifying the measure of differences; in fact it allows only ranking the objects of comparison.

The second approach is based on the index method, using the relative strength index. This method was firstly approved by the authors during revealing comparative dynamics of the Russian northern regions (Baranov \& Skufina, 2015). The essence of index methods is the transition from indicators expressed in economic (physical) units to dimensionless indices which are amenable to a visual comparison. From the standpoint of economic analysis of the differentiation of towns and districts, the most interesting is that index methods make it 
possible to trace and compare the actual rate of change. These properties of information are important for managing the regional development because, firstly, they characterize transformation processes; secondly, they are to a large extent an indicator of the effectiveness of management; and thirdly, they make it possible to compare with other objects (in our case, towns and regions).

The third approach is based on the calculation of the analogue of the Gini index traditionally used to study inequality of incomes. The authors propose to calculate the Gini index for each of the basic indicators of the Murmansk regional objects. This will allow considering deviations in the actual distribution of the values of the analyzed indicator by towns and districts of the Murmansk region from an absolutely equal distribution between towns and regions.

The phenomenon of differentiation in the socio-economic space of the Murmansk region has been considered on the basis of the comparative dynamics of the urban districts (in the research the authors also call them towns - Murmansk, Kovdor, Apatity, Kirovsk, Monchegorsk, Olenegorsk, Polyarnye Zori) and municipal districts (in the research the authors call them districts - Kola, Kandalaksha, Lovozero, Pechenga, Terskii).

The authors propose the following indicators of differentiation of towns and districts of the Murmansk region: 1) Investment into fixed assets of large and medium-sized organizations per capita; 2) Average retail turnover per capita; 3) Volume of commercial services to the population per capita; 4) Average monthly nominal gross payroll; 5) Number of registered crimes per mille; 6) Officially registered unemployed, by the end of year; 7) Number of doctors per mille, by the end of year; 8) The total area of living quarters on average per capita, by the end of year.

\section{Discussion and recommendations}

Discussion of the problem of differentiation between the towns and districts located in the Murmansk region is significant from the point of view of managing the territorial development.

The authors note that the analysis shows the stability of the differentiation between urban and municipal districts of the Murmansk region. That is, there is no reason to believe that any component of regional development can destabilize the regional socio-economic situation.

Thus, the first recommendation is, on the whole, to preserve the overall socio-economic policy and practice of managing the social and economic development of the Murmansk region determined with the strategic planning tasks. However, the peculiarities of differentiation that the authors have identified, for example, the coordinated behavior on the ratings of crime and unemployment and the growth of differentiation in some indicators of the social sphere indicate the need to strengthen attention to tactical goals. The authors are members of the Economic Council under the Governor of the Murmansk region and the Public Council under the Ministry of Economic Development of the Murmansk region and can argue that more attention is paid to discussing strategic objectives than to tactical goals. The results of this study are an argument for a practical recommendation to the regional government - to intensify the discussion of precisely the current problems, short-term plans and tasks for the development of the Murmansk region, its towns and districts. Also, it should be noted that the trends of regional differentiation characterize the goals of regional 


\section{DIFFERENTIATION OF SOCIO-ECONOMICAL}

management as socially-oriented. This is evidenced by low differentiation and the tendency of its further reduction in such indicators as "average retail turnover per capita", "the number of recorded crimes per mille people of the population", "officially registered unemployed", and "the total area of living quarters on average per capita". At the same time, attention is drawn to the growth of differentiation in terms of "the number of doctors per mille". Considering the significant territory of the region located in the Arctic, insufficient transport communication within the region, the reducing of the population's incomes (correspondingly, reduction of expenditures on disease prevention, quality nutrition, etc., which determines the increase in morbidity), this trend should be considered unconditionally negative.

Thus, the second recommendation is to prevent a further reduction in the number of medical organizations, especially those providing primary health care in the Murmansk region and preservation of the number of medical personnel. We recommend a list of activities that include a uniform increase in expenditures for the development of the regional health care infrastructure in the Murmansk region; a uniform strengthening of the material and technical base of medical institutions in the towns and districts of the region; making the contracts with medical universities for targeted training of doctors to reduce the staff deficit (especially acute, according to the rating, in Kirovsk, Kovdor, Lovozero, Pechenga, and Terskii districts), and improvement of social support measures for doctors working in remote areas and rural settlements.

Thus, the third recommendation is to preserve the guidelines for investment development in the Murmansk region and further strengthen the regional investment measures. The list of the measures proposed includes: 1) for large enterprises located in Kirovsk, Monchegorsk, Polyarnye Zori, Olenegorsk and Kandalaksha ñ the support of the effective and stable governmental regulation of prices and tariffs and diversification of the activities of these enterprises; 2) for small business - the reorientation of a part of the region's expenditures on the system of supporting the innovative activity of small business, concentrating mainly on the city of Murmansk, on the subsidy system for the municipalities of the Murmansk region aimed at the development of small and medium-sized business in all settlements in the Murmansk region. Besides, special attention should be given to increasing investment activity in remote, border areas to solve the problem of ensuring the development of the entire territory of the Murmansk region. This is a separate management work aimed at creating the conditions for using the potential of foreign economic and interregional relations, cross-border cooperation, tourism and trade in the interests of socio-economic development of the region and solving the problem of differentiation in development. The authors have submitted to the Murmansk regional authorities the proposals on the expediency of forming a special Program for socio-economic development of the cross-border and remote areas of the Murmansk region.

\section{Conclusion}

Summing up, the authors once again emphasize the fundamental and complex nature of the problem of unequal socio-economic development of any territorial object. It is the complexity of the problem of unequal development that dictates the need for its multifaceted consideration. The authors confirmed the first hypothesis that a systematic mapping of interregional differentiation problem on the regional socio-economic space requires the assessment methodological tools. In the study the authors applied a comprehensive 
assessment; examined the dynamics of the relative strength index for each of the assessment indicators and calculated the Gini index for each of the assessment indicators. The analysis of assessment results clearly reflected not only the specifics of the research object, but also the possibilities and limitations of the methodological tools used: the "average places" rating (integrated assessment) only ranks towns and districts; the "relative strength" rating quantitatively characterizes the dynamics of development of each object relative to the general group situation; the analog of the Gini index characterizes the measure of differences for each of the basic assessment indicators.

The second hypothesis was not confirmed that the crisis processes determine the displacements in the ratio of the socio-economic development parameters of towns and districts in the Murmansk region and lead to an increase in the differences in the economy 
assessment; examined the dynamics of the relative strength index for each of the assessment indicators and calculated the Gini index for each of the assessment indicators. The analysis of assessment results clearly reflected not only the specifics of the research object, but also the possibilities and limitations of the methodological tools used: the "average places" rating (integrated assessment) only ranks towns and districts; the "relative strength" rating quantitatively characterizes the dynamics of development of each object relative to the general group situation; the analog of the Gini index characterizes the measure of differences for each of the basic assessment indicators.

The second hypothesis was not confirmed that the crisis processes determine the displacements in the ratio of the socio-economic development parameters of towns and districts in the Murmansk region and lead to an increase in the differences in the economy 